\title{
Eficácia de extratos de nim para o controle do oídio do feijoeiro
}

\author{
Solange Monteiro de Toledo Piza Gomes Carneiro, Ericka Pignoni, \\ Maria Elizabeth da Costa Vasconcellos, José Carlos Gomes
}

Instituto Agronômico do Paraná, Cx. Postal 481, CEP 86001-970, Londrina, PR, email: solange_carneiro @ iapar.br. Apoio financeiro: Programa SEAB/Paraná-12 meses.

Autora para correspondência: Solange M. de T. Piza Gomes Carneiro

Data de chegada: 13/05/2005. Aceito para publicação em: 29/05/2006.

\section{RESUMO}

Carneiro, S.M. de T.P.G.; Pignoni, E.; Vasconcellos, M.E. da C.; Gomes, J.C. Eficácia de extratos de nim para o controle do oídio do feijoeiro. Summa Phytopathologica, v.33, n.1, p.34-39, 2007.

O nim, Azadirachta indica, vem sendo estudado nos últimos anos para o controle de fitopatógenos. O objetivo deste trabalho foi avaliar o efeito do óleo, do extrato de sementes e do extrato de folhas de nim no controle do oídio do feijoeiro, em casa de vegetação. Uma formulação comercial de óleo emulsionável de nim foi testada em concentrações entre 0,25 e 2,0\%, em aplicações antes ou após o surgimento dos sintomas da doença. O extrato de sementes foi produzido em laboratório por meio da trituração das sementes em água destilada, sendo pulverizado 48 horas antes ou 24 horas após a inoculação do patógeno. Avaliou-se, após o surgimento dos sintomas, a eficiência de uma formulação comercial de extrato de folhas, nas concentrações de 0,25 e $0,5 \%$. Verificou-se que o óleo de nim foi eficiente para o controle da doença quando aplicado antes ou depois do surgimento dos sintomas. O extrato de sementes controlou a doença nas três concentrações testadas. Por outro lado, o extrato de folhas não foi eficiente no controle do oídio do feijoeiro.

Palavras-chave adicionais: Azadirachta indica, controle alternativo, Phaseolus vulgaris, Erysiphe polygoni

\section{ABSTRACT}

Carneiro, S.M. de T.P.G.; Pignoni, E.; Vasconcellos, M.E. da C.; Gomes, J.C. Effectiveness of neem extracts in controlling the powdery mildew of bean plant. Summa Phytopathologica, v.33, n.1, p.34-39, 2007.

The neem, Azadirachta indica, has been studied in the last years for the use in controlling plant pathogens. The objective of this work was to evaluate the effect of the neem oil, seed kernel extract and leaf extract on the control of the powdery mildew of the bean plant under green house conditions. The emulsified neem oil was tested for concentrations between 0.25 and $2.0 \%$ and sprayed before or after the appearance of the symptoms of the disease. The seed kernel extract was produced under laboratory conditions by grinding the kernels in distilled water, which was sprayed 48 hours before or 24 hours after the inoculation of the pathogen. It was also evaluated the efficiency of a commercial leaf extract at the concentrations of 0.25 and $0.5 \%$ which was sprayed after the appearance of the symptoms. The results of this work showed that the neem oil was efficient in the control of the disease when applied before or after the appearance of the symptoms. The seed kernel extract controlled the disease at the three tested concentrations. On the other hand, the leaf extract was not efficient in the control of the powdery mildew of bean plant.
Em todo o mundo é crescente a procura por alimentos mais nutritivos e sem substâncias tóxicas, como resultado, entre outras coisas, da preocupação com a contaminação ambiental e dos alimentos, pelo uso indiscriminado de pesticidas na agricultura. A busca por produtos naturais que sejam eficientes no controle de doenças de plantas têm aumentado nos últimos anos, visando obter-se alternativas aos fungicidas sintéticos e que não apresentem os efeitos negativos destes últimos à saúde humana e ao meio ambiente.

Estudos têm demonstrado que óleos e extratos de folhas de algumas espécies vegetais são eficientes no controle de doenças de plantas, seja pela ação fungitóxica direta ou pelo aumento no nível de resistência às doenças da cultura tratada. Estas substâncias extraídas das plantas são mais baratas que os fungicidas, facilmente disponíveis ao agricultor, apresentam baixo risco de intoxicação humana e poluição do meio ambiente, podendo, em muitos casos, serem obtidas na própria propriedade agrícola (11). Estas características colocam os produtos naturais como excelente recurso para o controle de doenças de plantas na agricultura familiar ou na agricultura orgânica. Por outro lado, enquanto os produtores convencionais dispõem de uma ampla gama de produtos químicos para o controle de doenças e pragas nas lavouras, 
as opções disponíveis aos agricultores que utilizam sistemas de produção agroecológicos são reduzidas e pouco estudadas.

O nim, Azadirachta indica A. Juss., árvore da família Meliaceae, é conhecido há séculos, principalmente na Índia, por sua ação medicinal, e nas últimas décadas seu estudo têm se difundido devido às substâncias inseticidas presentes nas folhas e frutos. Dentre os mais de 40 terpenóides já identificados na planta que possuem ação contra insetos, a azadiractina é o composto mais eficiente. Esses compostos têm grande potencial no controle de pragas, apresentam toxicidade extremamente baixa aos vertebrados, sendo praticamente inócuos, causando baixo impacto ao ambiente. O plantio do nim está crescendo rapidamente no Brasil, com o objetivo de exploração da madeira e também para a produção de folhas e frutos, de onde se retira a matéria prima para produtos inseticidas, para uso medicinal, veterinário ou na indústria de cosméticos (11).

Além dos diversos usos já citados, o nim tem apresentado potencial para o controle de fitopatógenos (5). O efeito do nim sobre fungos é variável, dependendo, entre outros fatores, do patógeno alvo. Govindachari et al. (9), estudando a atividade antifúngica de terpenóides constituintes do óleo de nim, observaram que a azadiractina não afetou o crescimento de três fungos fitopatogênicos, enquanto que a salanina, nimbina, epoxiazadiradiona, deacetilnimbina e azadiradiona, apresentaram diferentes níveis de controle. Esses cinco terpenóides que foram eficazes no controle de fungos apresentaram maior ação quando em mistura do que quando testados isoladamente.

Nos últimos anos, vários artigos foram publicados avaliando a eficácia do nim para o controle de fungos como Pyricularia oryzae (2), Erysiphe pisi (14,17), Plasmopara viticola (19) e Alternaria helianthi (7), causadores de importantes doenças em culturas agrícolas. Carneiro (6) observou que o óleo de nim a $0,25 \%$ ou $0,5 \%$ controlou o oídio do tomateiro em casa de vegetação. Srinivas et al. (18) observaram que o óleo de nim a $0,5 \%$ e $1 \%$ controlou a cercosporiose do amendoim e aumentou a produção de maneira significativa em relação à testemunha. Bhutta et al. (4) avaliaram o efeito do nim no controle de fungos em sementes de girassol. Os autores verificaram que uma solução a 1\% obtida a partir de sementes de nim reduziu em quase $100 \%$ a porcentagem de incidência de A. alternata nas duas cultivares estudadas, além de controlar outros fungos como Fusarium spp. O extrato de sementes de nim a $0,5 \%$ e $1 \%$ in vitro, inibiu o crescimento de Alternaria alternata e Macrophomina phaseolina (3).

O óleo de nim tem sido estudado também no controle de bactérias. Abbasi et al. (1) verificaram que o óleo de nim foi eficiente no controle de Xanthomonas campestris pv. vesicatoria em tomate e pimentão em casa de vegetação. Em condições de campo, tanto óleo de nim a 0,5\% quanto o acibenzolar-S-metil pulverizados semanalmente foram eficientes no controle deste patógeno.

No Paraná a área cultivada sob sistemas alternativos de produção tem aumentado bastante nos últimos anos. O feijoeiro é uma cultura importante nestas propriedades, seja para consumo interno ou exportação, e algumas variedades utilizadas, como a cultivar Iapar-31, são particularmente suscetíveis ao oídio. O objetivo deste trabalho foi avaliar a eficiência do nim no controle do oídio do feijoeiro, em condições de casa de vegetação.

\section{MATERIAL E MÉTODOS}

Todos os ensaios foram realizados em casa de vegetação na estação experimental do IAPAR em Londrina-PR. A cultivar IAPAR-31 foi semeada em vasos contendo uma mistura de solo, areia e esterco de curral, e, exceto quando mencionado, foram utilizados nos experimentos vasos contendo duas plantas, quando estas estavam nos estádios V3 V4 de desenvolvimento (10). Em todos os ensaios em que foi utilizado o óleo de nim, foi empregada uma marca comercial de óleo emulsionável contendo $0,5 \%$ de azadiractina. $\mathrm{O}$ fungicida utilizado como testemunha foi o triforine na dose de $4 \mathrm{ml} / \mathrm{L}$. Todos os ensaios foram realizados em delineamento inteiramente casualizado. Os dados foram transformados em $\sqrt{(x+0,5)}$ para a realização da análise estatística, e as médias foram comparadas pelo teste Tukey a $5 \%$ de probabilidade.

\section{Experimento I:}

Para avaliar a eficácia do óleo de nim em pulverizações preventivas, plantas de feijoeiro foram aspergidas, utilizando-se um pulverizador manual, com os seguintes tratamentos: óleo de nim nas concentrações de $0,5,1,0$ e 1,5\%, fungicida e água. Os cinco tratamentos foram repetidos em três grupos com pulverização 78, 54 e $6 \mathrm{~h}$ antes da inoculação do patógeno. As plantas foram inoculadas com suspensão de conídios na concentração de $3 \times 10^{4}$ esporos $/ \mathrm{ml}$, sendo a seguir mantidas por $24 \mathrm{~h}$ em sala climatizada em regime $12 \mathrm{~h}$ de luz/12h de escuro, temperatura de $20^{\circ} \mathrm{C} \pm 2{ }^{\circ} \mathrm{C}$ e umidade relativa de aproximadamente $80 \%$. O experimento foi realizado em esquema fatorial ( $3 \times 5)$ com quatro repetições, sendo cada repetição constituída de um vaso, num total de 60 vasos. A avaliação da doença foi feita 11 dias após a inoculação, por meio da contagem do número de manchas com sinais do patógeno nas quatro folhas basais de cada planta.

\section{Experimento II:}

Para verificar a eficácia do óleo de nim quando aplicado após o contato do patógeno com o hospedeiro, plantas de feijoeiro foram pulverizadas óleo de nim nas concentrações de $0,5,1,0$ e 1,5\%, fungicida e água. Os cinco tratamentos foram repetidos em três grupos com pulverização 48, 96 e 168h após a inoculação do patógeno. As plantas foram inoculadas com suspensão de conídios na concentração de $4 \mathrm{X}$ $10^{4}$ esporos $/ \mathrm{ml}$, sendo a seguir mantidas por $24 \mathrm{~h}$ em uma sala climatizada em regime $12 \mathrm{~h}$ de luz $/ 12 \mathrm{~h}$ de escuro, temperatura de $20^{\circ} \mathrm{C}$ $\pm 2^{\circ} \mathrm{C}$ e umidade relativa de aproximadamente $80 \%$. O experimento foi realizado em esquema fatorial ( $3 \times 5)$ com quatro repetições, num total de 60 vasos. A avaliação da doença foi feita nove dias após a inoculação, por meio da contagem do número de manchas com sinais do patógeno nas quatro folhas basais de cada planta.

\section{Experimento III:}

Nesse experimento avaliou-se a eficiência do óleo de nim quando pulverizado após o surgimento dos sintomas da doença. Plantas com a segunda folha trifoliolada foram inoculadas com suspensão de conídios na concentração de $2 \times 10^{4}$ esporos $/ \mathrm{ml}$, sendo a seguir mantidas em sala climatizada por $24 \mathrm{~h}$ nas condições já descritas nos experimentos I e II. Após este período as mesmas foram transferidas para o telado. Nove dias após a inoculação foi feita a primeira avaliação, contandose o número de manchas com sinais do patógeno nas folhas. A seguir foi feita a pulverização dos seguintes tratamentos: água, fungicida e óleo de nim a $0,5,1,0$ e 2,0\%. O experimento foi realizado com seis repetições. Dois dias após a pulverização foi feita a segunda avaliação dos sintomas, utilizando o mesmo critério dos experimentos anteriores.

\section{Experimento IV:}

Esse experimento foi instalado para verificar o efeito do número de pulverizações na eficiência do óleo de nim no controle da doença. As plantas foram inoculadas com suspensão de esporos na concentração de $3 \times 10^{4}$ conídios $/ \mathrm{ml}$ e mantidas por $24 \mathrm{~h}$ em sala climatizada. A seguir as plantas foram levadas para casa de vegetação e divididas em 
dois grupos: o grupo I foi pulverizado aos nove dias após a inoculação (d.a.i.) e 18 d.a.i., e o grupo II recebeu os tratamentos aos 9, 14, 18 e 21 d.a.i. Os tratamentos foram água, fungicida e óleo de nim a 0,25, 0,5 e $1,0 \%$. Utilizaram-se cinco repetições por tratamento, num total de 50 vasos. O experimento foi realizado em esquema fatorial $(2 \times 5)$. Para aumentar o inóculo sobre as plantas avaliadas foram distribuídos vasos com plantas com alta severidade de oídio nas mesas na casa de vegetação. $\mathrm{O}$ ventilador foi mantido ligado e estes vasos foram mudados de lugar várias vezes na semana para casualizar a distribuição de esporos. Nove dias após a inoculação foi feita a primeira avaliação de severidade através da estimativa visual de porcentagem de área foliar com sinais do patógeno, para verificar a uniformidade dos sintomas nas plantas. A seguir foi feita a primeira pulverização dos tratamentos nas plantas dos dois grupos. Outras duas avaliações da severidade da doença foram feitas aos sete dias e aos 14 dias após a primeira pulverização.

\section{Experimento V:}

Para verificar a eficiência do extrato de sementes no controle do oídio foram coletadas sementes de nim na estação experimental do IAPAR em Paranavaí (PR), em março de 2003. Os tratamentos testados foram: extrato de sementes de nim nas proporções de 35, 25 e 15g/L, água e fungicida. Para o preparo do extrato, as sementes foram trituradas em liqüidificador com água destilada esterilizada, deixadas em repouso por um período de 20 a $24 \mathrm{~h}$, sendo o caldo filtrado após este período. Os tratamentos foram pulverizados com pulverizador manual $48 \mathrm{~h}$ antes da inoculação do patógeno. Foram utilizados cinco tratamentos e sete repetições, cada repetição representada por um vaso com uma planta. O inóculo, na concentração de $2 \times 10^{4}$ conídios $/ \mathrm{ml}$, foi pulverizado sobre as plantas, que a seguir foram mantidas em sala climatizada por $24 \mathrm{~h}$, e então transferidas para casa de vegetação. Avaliou-se o ensaio 13 d.a.i., por meio da contagem do número de manchas com sinais do patógeno em cada folha.

Os mesmos tratamentos, condições do experimento e delineamento experimental foram utilizados para avaliar o efeito do extrato de sementes quando pulverizado $24 \mathrm{~h}$ após a inoculação, em outras 35 plantas. Doze dias após a inoculação foi feita a avaliação da severidade da doença por meio da estimativa visual da porcentagem de área foliar com sintomas e sinais do patógeno.

\section{Experimento VI:}

Nesse experimento comparou-se a eficiência de um extrato de folhas comercial nas doses de 0,25 e $0,5 \%$ com o óleo emulsionável de nim nas concentrações de 0,25 e $0,5 \%$. As testemunhas utilizadas foram fungicida e água. Foram utilizadas seis repetições, cada repetição representada por um vaso com uma planta. As plantas não necessitaram de inoculação pois apresentavam alta infecção natural quando foram pulverizadas. Foram feitas duas pulverizações, com intervalo de sete dias entre as mesmas. Foi feita uma avaliação preliminar da severidade dos sintomas um dia antes do início das pulverizações, para confirmar a distribuição homogênea da doença entre as parcelas experimentais. Outras duas avaliações da severidade dos sintomas foram feitas aos seis dias após a primeira aplicação dos tratamentos e um dia após a segunda pulverização dos tratamentos.

\section{RESULTADOS E DISCUSSÃO}

A pulverização preventiva do óleo de nim resultou em efeito significativo da época de aplicação $(\mathrm{P} \leq 0,05)$ e dos tratamentos utilizados $(\mathrm{P} \leq 0,01)$ sobre o número de manchas de oídio/folha (Figura 1), mas a interação entre tratamentos e época não foi significativa. A pulverização dos tratamentos $6 \mathrm{~h}$ antes da inoculação diminuiu
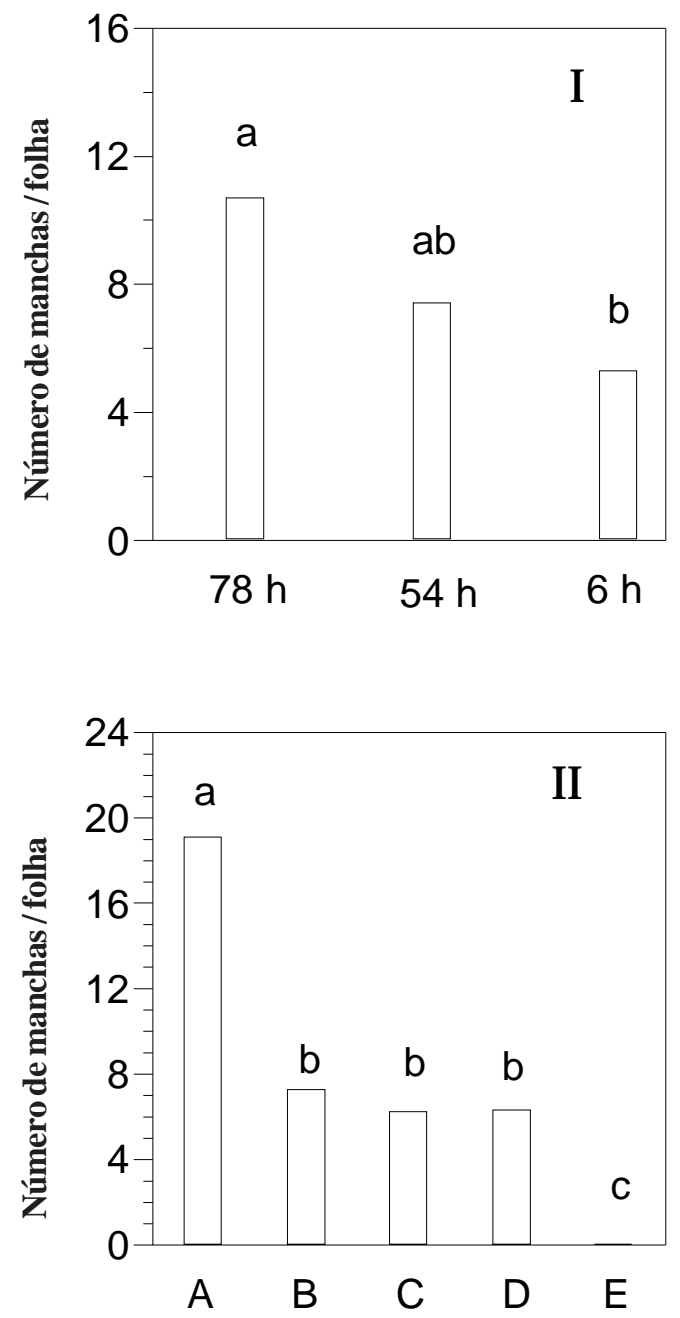

Figura 1. Efeito do óleo de nim em pulverização preventiva sobre o número médio de manchas de oídio/folha em feijoeiros. (I): Efeito médio do tempo entre a pulverização dos tratamentos e a inoculação do patógeno. (II): Efeito médio dos tratamentos. $\mathrm{A}=$ água; $\mathrm{B}=$ óleo de nim a $0,5 \% ; \mathrm{C}=$ óleo de nim a $1,0 \% ; \mathrm{D}=$ óleo de nim a $1,5 \% ; \mathrm{E}=$ fungicida. Médias seguidas pela mesma letra não diferem entre si pelo teste de Tukey a $5 \%$.

significativamente o número de manchas e sinais do patógeno nas folhas quando comparada com a pulverização $78 \mathrm{~h}$ antes da inoculação. A diminuição do efeito protetor do óleo de nim com o passar do tempo pode ser explicada pela degradação provocada pelos raios solares e altas temperaturas dos compostos ativos (11). As três concentrações do óleo emulsionável de nim reduziram o número médio de manchas de oídio/folha quando comparados com a testemunha, mas o fungicida foi superior ao nim. A aplicação do óleo de nim reduziu, em média, $65 \%$ a intensidade da doença quando comparada à água. Observaramse sintomas de fitotoxicidade em algumas plantas dos tratamentos em que o óleo de nim foi aplicado nas concentrações de 1 e 1,5\%.

Quando os tratamentos foram aplicados após a inoculação do patógeno, não foi observada diferença entre os três períodos de tempo avaliados e não houve interação entre os tratamentos, mas houve efeito dos tratamentos $(\mathrm{P} \leq 0,01)$ na redução do número de manchas de oídio/ folha. O óleo de nim aplicado nas concentrações de $0,5,1,0$ e 1,5\% foi tão eficiente quanto o fungicida no controle do oídio do feijoeiro (Figura 2), tendo reduzido em média, $97 \%$ do número de manchas/folha. 


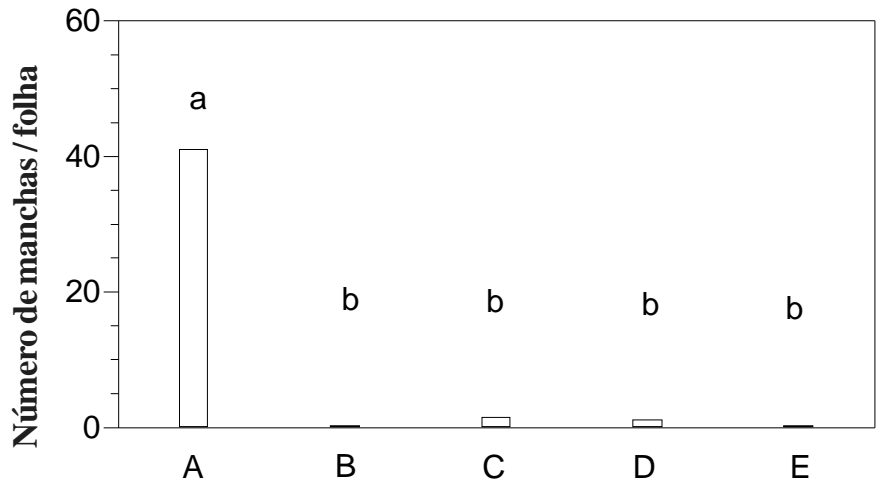

Figura 2. Efeito do óleo de nim pulverizado após a inoculação do patógeno sobre o número de manchas de oídio/folha em feijoeiros. A = água; $\mathrm{B}=$ fungicida; $\mathrm{C}=$ óleo de nim a $0,5 \% ; \mathrm{D}=$ óleo de nim a $1,0 \% ; \mathrm{E}$ $=$ óleo de nim a 1,5\%. Médias seguidas pelas mesmas letras não diferem entre si pelo teste Tukey a $5 \%$.

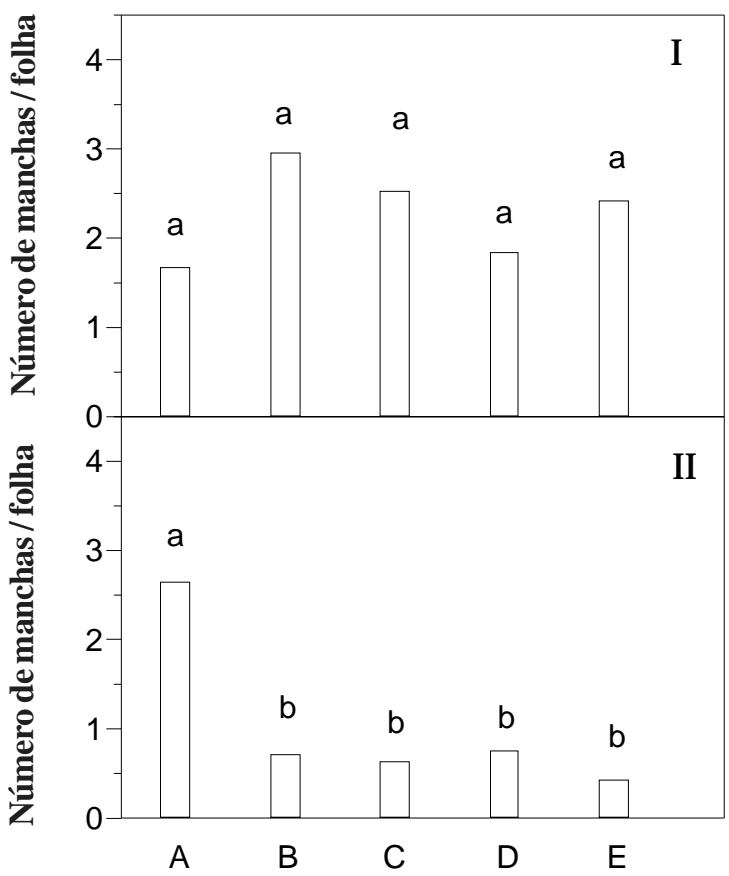

Figura 3. Efeito do óleo de nim sobre o número de manchas de oídio/ folha em feijoeiros quando os tratamentos foram aplicados após o surgimento dos sintomas. I: Avaliação antes da pulverização; II: Avaliação dois dias após a pulverização. $\mathrm{A}=$ água; $\mathrm{B}=$ fungicida; $\mathrm{C}=$ óleo de nim a $0,5 \% ; \mathrm{D}=$ óleo de nim a $1,0 \% ; \mathrm{E}=$ óleo de nim a $2 \%$. Médias seguidas pela mesma letra não diferem entre si pelo teste Tukey a $5 \%$.

No experimento III o número de manchas de oídio/folha foi estatisticamente semelhante em todas as plantas antes da pulverização dos tratamentos (Figura 3I), indicando que a distribuição da doença foi homogênea nas parcelas experimentais. Na segunda avaliação, observou-se que o óleo de nim foi semelhante ao fungicida no controle da doença, nas três concentrações testadas, (Figura 3II) tendo reduzido em aproximadamente $77 \%$ o número de manchas de oídio/folha.

No experimento IV, a severidade da doença avaliada antes do início das pulverizações foi semelhante entre os tratamentos, indicando a distribuição homogênea da doença nas parcelas experimentais no momento da pulverização. Não se observou diferença significativa entre o número de pulverizações (grupo I e grupo II) nas duas avaliações seguintes, indicando que uma pulverização semanal foi semelhante a duas pulverizações semanais no controle da doença, nas condições desse experimento (Tabela 1). Também nesse ensaio as três concentrações do óleo de nim assim como o fungicida controlaram a doença, não tendo diferido entre si.

Segundo esses experimentos, o óleo de nim controla o oídio do feijoeiro em casa de vegetação, o que reforça os resultados obtidos por outros autores, ao mostrarem que o óleo de nim é um produto com ação contra diversos oídios, como o do tomateiro (6), da ervilha $(14,17)$, do pepino (19) e da roseira (12). A alta eficiência do óleo de nim em pulverizações após o contato do patógeno com o hospedeiro ou após o surgimento dos sintomas mostra a ação direta do produto sobre o patógeno, como já observado para outros fungos $(2,3,4)$. Por outro lado, alguns autores têm observado alterações na atividade de enzimas e acumulação de compostos fenólicos em plantas tratadas com óleo de nim, sugerindo que o produto atuaria indiretamente, por meio da indução de reações de defesa da planta $(1,13,17)$. Os resultados do presente trabalho não permitem conclusões a este respeito, mas estudos futuros neste sentido devem levar em consideração o fato de que os compostos ativos do nim podem ser sistêmicos em plantas $(8,15,20)$.

O extrato de sementes de nim foi eficiente no controle do oídio quando aplicado $48 \mathrm{~h}$ antes e 24h após a inoculação (Tabela 2). Quando aplicado antes, as três concentrações foram semelhantes entre si, mas não apresentaram a mesma eficiência do fungicida. Quando o extrato de sementes foi pulverizado após a inoculação, as três concentrações foram tão eficientes quanto o fungicida (Tabela 2). $\mathrm{O}$ extrato de sementes reduziu os sintomas de oídio em aproximadamente $82 \%$ na aplicação preventiva e em $98 \%$ na pulverização realizada após a inoculação. Este resultado corrobora aquele obtido por Steinhauer (19) e Rovesti et al. (16), que verificaram que o extrato aquoso de sementes de nim aplicado na concentração de $25 \mathrm{~g} / \mathrm{L}$ controlou o oídio do pepino (19) e, na concentração de $20 \mathrm{~g} / \mathrm{L}$ o ódio da abobrinha, do trigo e da cevada (16). No presente experimento, o extrato de sementes na concentração de $35 \mathrm{~g} / \mathrm{L}$ apresentou leve encarquilhamento das folhas em algumas plantas. Apesar desta fitotoxicidade apresentada pelo nim em casa de vegetação é possível que em campo isto não ocorra devido às diferenças nas condições ambientais. Abbasi et al. (1) observaram que o óleo de nim foi fitotóxico em tomate em casa de vegetação, mas em campo este fato não se repetiu, sendo que o produto foi eficiente no controle de Xanthomonas campestris pv. vesicatoria em casa de vegetação e em campo.

A severidade dos sintomas nas plantas do experimento VI era semelhante entre os tratamentos antes da primeira pulverização (Tabela 3). Na avaliação realizada seis dias após o início dos tratamentos, as duas concentrações do extrato de folhas e o óleo de nim a $0,25 \%$ não diferiram da testemunha. Apenas o óleo de nim a $0,5 \%$ e o fungicida foram eficientes no controle da doença. Após a segunda pulverização, observou-se que o tratamento com o óleo de nim a $0,25 \%$ apresentou controle da doença, e o óleo de nim a $0,5 \%$ foi semelhante ao fungicida no controle do oídio. A redução da severidade da doença pelo óleo de nim foi de $79 \%$ na concentração de $0,25 \%$ e de $90 \%$ na concentração de $0,5 \%$, oito dias após o início dos tratamentos. O extrato de folhas não controlou o oídio nas duas concentrações avaliadas. Esse resultado difere do obtido por Paul \& Sharma (13) que obtiveram controle de Drechslera graminea em cevada com extrato de folhas de nim e de Amadioha (2), que obteve controle da brusone do arroz também com extrato de folhas. No entanto, deve-se considerar que a forma de preparo dos extratos e a concentração testada são diferentes em cada trabalho, o que influi no resultado observado.

Os resultados deste trabalho mostraram que o extrato de folhas de nim não foi eficiente no controle do oídio do feijoeiro e que o óleo de nim e o extrato de sementes de nim controlaram a doença em casa de 
Tabela 1. Efeito do número de pulverizações do óleo de nim nas concentrações de $0,25 \%$, $0,5 \%$ e $1,0 \%$ sobre a severidade do oídio do feijoeiro. As

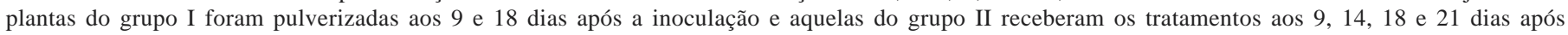
a inoculação.

\begin{tabular}{|c|c|c|c|c|c|c|}
\hline \multirow{3}{*}{ Tratamentos } & \multicolumn{6}{|c|}{ Severidade $(\%)$} \\
\hline & \multicolumn{3}{|c|}{7 dias após a primeira pulverização } & \multicolumn{3}{|c|}{14 dias após a primeira pulverização } \\
\hline & grupo I & grupo II & Média & grupo I & grupo II & Média \\
\hline Água & 4,2 & 3,6 & 3,90 a & 4,5 & 4,6 & 4,55 a \\
\hline Fungicida & 1,5 & 1,2 & $1,35 \mathrm{~b}$ & 1,1 & 1,1 & $1,10 \mathrm{~b}$ \\
\hline $\operatorname{Nim} 0,25 \%$ & 1,7 & 1,9 & $1,80 \mathrm{~b}$ & 1,5 & 1,3 & $1,40 \mathrm{~b}$ \\
\hline $\operatorname{Nim} 0,5 \%$ & 2,0 & 1,8 & $1,90 \mathrm{~b}$ & 1,6 & 1,1 & $1,35 \mathrm{~b}$ \\
\hline $\operatorname{Nim} 1,0 \%$ & 1,9 & 1,4 & $1,65 \mathrm{~b}$ & 1,6 & 1,0 & $1,30 \mathrm{~b}$ \\
\hline Média & $2,26 \mathrm{~A}$ & $1,98 \mathrm{~A}$ & & $2,06 \mathrm{~A}$ & $1,82 A$ & \\
\hline
\end{tabular}

Médias seguidas pela mesma letra maiúscula na horizontal e minúscula na vertical não diferem entre si pelo teste Tukey a 5\%.

Tabela 2. Efeito do extrato de sementes de nim sobre o oídio do feijoeiro em duas épocas de pulverização. I: Pulverização $48 \mathrm{~h}$ antes da inoculação. II: pulverização $24 \mathrm{~h}$ após a inoculação.

\begin{tabular}{lcc}
\hline & $\mathrm{N}^{\circ}$ de manchas / folha & Severidade (\%) \\
\hline Tratamentos & $\mathrm{I}$ & $\mathrm{II}$ \\
\hline Água & $8,88 \mathrm{a}$ & $6,18 \mathrm{a}$ \\
Fungicida & $0,00 \mathrm{c}$ & $0,00 \mathrm{~b}$ \\
Extrato de sementes a $35 \mathrm{~g} / \mathrm{L}$ & $1,84 \mathrm{~b}$ & $0,06 \mathrm{~b}$ \\
Extrato de sementes a $25 \mathrm{~g} / \mathrm{L}$ & $1,52 \mathrm{~b}$ & $0,03 \mathrm{~b}$ \\
Extrato de sementes a $15 \mathrm{~g} / \mathrm{L}$ & $1,38 \mathrm{~b}$ & $0,17 \mathrm{~b}$ \\
\hline
\end{tabular}

Médias seguidas pela mesma letra não diferem entre si pelo teste Tukey a $5 \%$.

Tabela 3. Efeito do extrato de folhas e do óleo de nim sobre a severidade do ó́dio do feijoeiro. Os tratamentos foram pulverizados duas vezes com intervalo de sete dias.

\begin{tabular}{lccc}
\hline \multicolumn{4}{c}{ Severidade (\%) } \\
\hline Tratamentos & $\begin{array}{c}\text { Um dia antes do } \\
\text { tratamento }\end{array}$ & $\begin{array}{c}\text { Seis dias após o início } \\
\text { do tratamento }\end{array}$ & $\begin{array}{c}\text { Oito dias após o } \\
\text { início do tratamento }\end{array}$ \\
\hline Água & $16,9 \mathrm{a}$ & $21,5 \mathrm{a}$ & $25,9 \mathrm{a}$ \\
Fungicida & $23,9 \mathrm{a}$ & $5,2 \mathrm{c}$ & $0,0 \mathrm{c}$ \\
Extrato de folhas a 0,25\% & $26,0 \mathrm{a}$ & $20,7 \mathrm{a}$ & $21,3 \mathrm{a}$ \\
Extrato de folhas a 0,5\% & $16,7 \mathrm{a}$ & $16,4 \mathrm{ab}$ & $20,0 \mathrm{a}$ \\
Óleo de nim a 0,25\% & $22,1 \mathrm{a}$ & $10,2 \mathrm{abc}$ & $5,2 \mathrm{~b}$ \\
Óleo de nim a 0,5\% & $16,4 \mathrm{a}$ & $6,9 \mathrm{bc}$ & $2,5 \mathrm{bc}$ \\
\hline
\end{tabular}

Médias seguidas pela mesma letra não diferem entre si pelo teste Tukey a 5\%.

vegetação e podem ser uma boa alternativa para uso em cultivos agroecológicos.

\section{REFERÊNCIAS BIBLIOGRÁFICAS}

1.Abbasi, P.A.; Cuppels, D.A.; Lazarovits, G. Effect of foliar applications of neem oil and fish emulsion on bacterial spot and yield of tomatoes and peppers. Canadian Journal Plant Pathology, Ottawa, v.25, p.41-48, 2003.

2.Amadioha, A.C. Controlling rice blast in vitro and in vivo with extracts of Azadirachta indica. Crop Protection, Surrey, v.19, n.5, p.287-290, 2000.

3.Bhutta, A.R.; Bhatti, M.H.R.; Iftikhar, A. Effect of seed diffusates on growth on seed-borne fungi of sunflower. Helia, Novi Sad, v.22, n.31, p.143-149, 1999.

4.Bhutta, A.R.; Bhatti, M.H.R.; Iftikhar, A. Effect of seed diffusates on fungal population and germination of sunflower seeds. Hélia, Novi Sad, v.24 n.34, p.77-81, 2001.

5.Carneiro, S.M. de T.P.G. Ação do nim sobre fungos fitopatogênicos. In: Martinez, S.S. O Nim - Azadirachta indica: natureza, usos múltiplos, produção. Londrina: Instituto Agronômico do Paraná, 2002. p. 59-64.

6.Carneiro, S.M. de T.P.G. Efeito de extratos de folhas e do óleo de nim sobre o oídio do tomateiro. Summa Phytopathologica, Botucatu, v.29, n.3, p.262-265, 2003.

7.Chattopadhyay, C. Yield loss attributable to Alternaria blight of sunflower (Helianthus annuus L.) in India and some potencially effective control measures. International Journal of Pest Management, London, v.45, n.1, p.15-21, 1999.

8.Gonçalves-Gervásio, R. de C.R. Efeito de extratos de Trichilia pallida Swartz e Azadirachta indica A. Juss (Meliaceae) sobre Tuta absoluta (Meyrick) e seu parasitóide Trichogramma preti- 
osum Riley. 2003. 88p. Tese (Doutorado em Entomologia) - Escola Superior de Agricultura Luiz de Queiroz, USP, Piracicaba.

9.Govindachari, T.R.; Suresh, G.; Gopalakrishnan, G.;Banumathy, B.; Masilamani, S. Identification of antifungal compounds from the seed oil of Azadirachta indica. Phytoparasitica, Bet Dagan, v.26, n.2, p.109-116, 1998.

10.Mariot, E.J. Aptidões climáticas, ideotipos e épocas de cultivo do feijoeiro no Paraná. In: Instituto Agronômico do Paraná, Feijão: tecnologia de produção. Londrina, 2000. p. 5-13.

11. Martinez, S. S. O Nim - Azadirachta indica: natureza, usos múltiplos, produção. Londrina: Instituto Agronômico do Paraná, 2002. 142p.

12.Pasini, C.; D’Aquila, F.; Curir, P.; Gullino, M.L. Effectiveness of antifungal compounds against rose powdery mildew (Sphaerotheca pannosa var. rosae) in glasshouses. Crop Protection, Surrey, v. 16, n. 3, p. 251-256, 1997.

13.Paul, P.K.; Sharma, P.D. Azadirachta indica leaf extract induces resistance in barley against leaf stripe disease. Physiological and Molecular Plant Pathology, Orlando, v.61, n.1, p.3-13, 2002.

14.Prithiviraj, B.; Singh, U.P.; Singh, K.P.; Plank-Schumacher, K. Field evaluation of ajoene, a constituent of garlic (Allium sativum) and neemazal, a product of neem (Azadirachta indica) for the control of powdery mildew (Erysiphe pisi) of pea (Pisum sativum). Zeitschrift für Pflanzenkrankheiten und Pflan- zenschutz, Stuttgart, v. 105, n.3, p.274-278, 1998.

15.Rovesti, L.; Deseö, K.V. Effectiveness of neem seed kernel extract against Leucoptera malifoliella Costa (Lep., Lyonetiidae). Journal of Applied Entomology, Hamburg, v.111, p.231-236, 1992.

16.Rovesti, L.; Di Marco, S.; Pancaldi, D. Effect of neem kernel extract on some phytopathogenic fungi under greenhouse conditions. Zeitschrift für Pflanzenkrankheiten und Pflanzenschutz, Sttutgart, v.99, n.3, p.293-296, 1992.

17.Singh, U.P.; Prithiviraj, B. Neemazal, a product of neem (Azadirachta indica), induces resistance in pea (Pisum sativum) against Erysiphe pisi. Physiological and Molecular Plant Pathology, London, v. 51, n.3, p.181-194, 1997.

18.Srinivas, T.; Rao, M.S.; Reddy, P.S.; Reddy, P.N. Comparative effects of plant extracts and chemicals of the management of leaf spot of groundnut (Arachis hypogaea L.) Tropical Agriculture, London, v. 77, p.58-60, 2000.

19.Steinhauer, B. Possible ways of using the neem tree to control phytopathogenic fungi. Plant Research and Development, Hamburg, v. 50, p. 83-92, 1999.

20.Sundaram, K.M.S.; Campbell, R.; Sloane, L.; Studens, J. Uptake, translocation, persistence and fate of azadirachtin in aspen plants (Populus tremuloides Michx.) and its effect on pestiferous twospotted spider mite (Tetranychus urticae Koch). Crop Protection, Surrey, v.14, n.5, p.415-421, 1995. 